* Doutora em Direito em 2014 pela Universidade de São Paulo (USP).

Mestre em Direito em 2010 pela Universidade Federal de Minas Gerais (UFMG).

Graduada em Direito em 2008 pela Universidade Federal de Minas Gerais (UFMG).

Email: ccapucio@usp.br

**Doutora em Direito em 2015 pela Pontifícia Católica de Minas Gerais (PUCMINAS).

Mestre em Direito em 2006 pela Université Panthéon-Assas (Paris, França).

Especialista em Direito em 2004 pela Université Panthéon-Assas (Paris, França). Graduada em Direito em 2002 pela Faculdades Milton Campos (FMC).

Email: fernandakallas@hotmail.com

\section{O Acordo da Omc Sobre Tecnologia DA INFORMAÇÃo (ITA) E SUA EXPANSÃo \\ (Ita II): Multilateralização do REgIONALISMO}

WTO's INFORMATION TECHNOLOGY AgreEMENT (ITA) AND ITS EXPANSION (ITA II): Multilateralizing Regionalism

Camilla Capucio* Fernanda de Araújo Kallas e Caetano**

Como citar: CAPUCIO, Camilla; KALLAS E CAETANO, Fernanda de Araújo. O Acordo da OMC sobre Tecnologia da Informação (ITA) e sua expansão (ITA II): multilateralização do regionalismo. Scientia Iuris, Londrina, v. 22, n. 1, p. 283-313, mar. 2018. DOI: $10.5433 / 2178-8189.2018 v 22$ n1p283. ISSN: $2178-8189$

Resumo: Tendo em vista o contexto da relação entre o multilateralismo e o regionalismo, a celebração de acordos plurilaterais no âmbito da Organização Mundial do Comércio, abertos à participação dos membros interessados, oferece uma perspectiva de multilateralização do regionalismo, na qual os benefícios dos consensos parciais podem ser estendidos à esfera multilateral. O ITA (Information Technology Agreement) - Acordo sobre Tecnologia da Informação é citado como exemplo desta possibilidade, e sua expansão, por meio da 
criação do ITA II, demonstra o fortalecimento desta tendência de multilateralização do regionalismo, embora com características especiais. Assim, o artigo se desenvolve buscando contextualizar e introduzir a temática do regionalismo e do multilateralismo, para em seguida apresentar a teoria da multilateralização do regionalismo e o ITA como uma dessas experiências, e a sua recente expansão como uma retomada da relevância de tal teoria. Diante dos impasses para conclusão da Rodada de Doha, a expansão desses consensos parciais e a continuidade das negociações na Organização Mundial do Comércio por meio da celebração de acordos plurilaterais setoriais tem se apresentado como uma possível saída, o que demanda uma rearquitetura da interpretação do papel da OMC na governança econômica global.

Palavras-chave: Organização Mundial do Comércio (OMC). Multilateralização do regionalismo. Acordos regionais de comércio. Acordo sobre tecnologia da informação (ITA). Acordos plurilaterais.

Abstract: Bearing in mind the complex context of the relationship between multilateralism and regionalism, the conclusion of plurilateral agreements within the WTO, open to participation of all interested members, offers a multilateral perspective of regionalism, in which the benefits of partial consensus are to 
be extended to the multilateral sphere. The ITA - Information Technology Agreement - is mentioned as an example of this possibility, and its recent expansion, through the negotiation of the ITA II, demonstrates the strengthening of this multilateralisation trend of regionalism, although with special features. Thus, this article is developed drawing the context and introduction of the theme of regionalism and multilateralism, and presents the theory of multilateralisation of regionalism and the ITA as one of those experiences, and its recent expansion as a resumption of the relevance of this theory. Considering the impasses for the conclusion of the Doha Round, the expansion of these partial consensus and the continuation of negotiations at the World Trade Organization by the conclusion of sectoral plurilateral agreements emerges as a possible way out, which demands a re-architecture of the interpretation of the role of the WTO in the global economic governance.

Key-words: World Trade Organization(WTO). Multilateralizing regionalism. Regional trade agreements. Information Technology Agreement (ITA); Plurilateral agreements. 


\section{INTRODUÇÃO}

Na Reunião Ministerial de Nairobi foi noticiada a celebração de um acordo no âmbito da OMC com o intuito de redução tarifária de produtos tecnológicos - o ITA (Information Technology Agreement) em relação ao qual o Brasil permaneceu apartado, não sem a crítica de diversos setores nacionais.

$\mathrm{Na}$ realidade, o que ocorreu em julho de 2015 foi a expansão de um acordo pré-existente, que completa neste ano duas décadas de existência, e que pode indicar a expansão de uma tendência identificada há alguns anos pela doutrina: o fenômeno de multilateralização do regionalismo, no âmbito da Organização Mundial do Comércio.

O regionalismo é um fenômeno inegável e crescente das relações econômicas internacionais, que se desenvolve em um contexto de multilateralismo econômico norteado pelo sistema GATT-OMC. Neste contexto, surgiu a teoria da multilateralização do regionalismo, teoria que busca reconhecer a possibilidade de apropriação multilateral dos compromissos alcançados em âmbitos regionais.

O acordo sob análise é um exemplo desta multilateralização do regionalismo, e, portanto, merece um estudo sobre sua expansão e concretização no comércio internacional, a partir da contextualização de sua existência e significado, tendo em conta a complexa relação entre as perspectivas multilateral e regional de liberalização comercial.

\section{CONTEXTO DA DISCUSSÃO: REGIONALISMO X MULTILATERALISMO}

Não é recente a preocupação de estudiosos com o futuro do sistema multilateral, tendo em vista a proliferação dos Acordos Regionais 
de Comércio - também denominados Acordos Preferenciais de Comércio.

Contudo, a percepção de que a formação de tais acordos tem acontecido de maneira livre e sem nenhuma ou com pouquíssima regulamentação efetiva tem levado a maioria da doutrina a vislumbrar uma inversão nas relações econômicas internacionais, na qual o regionalismo perde seu caráter de exceção, constituindo-se como uma regra, em potencial ameaça ao multilateralismo.

Tal inversão foi reconhecida, por exemplo, no relatório acerca do futuro da OMC - denominado Sutherland Report, em referência ao seu coordenador ${ }^{\prime}-$, como um dos principais desafios institucionais da organização no novo milênio:

Yet nearly five decades after the founding of the GATT, MFN is no longer the rule; it is almost the exception. Certainly, much more trade between the major economies is still conducted on an MFN basis. However, what has been termed the "spaguetti bowl" of custom unions, common markets, regional and bilateral free trade areas, preferences and an endless assortment of miscellaneous trade deals has almost reached the poit where $M F N$ treatment is exceptional treatment. Certainly the term might now be better defined as LFN, Least-FavoredNation treatment. Does it matter? We belive it matters profoundly to the future of the WTO (SUTHERLAND et al., 2004, p. 19).

De fato, o aumento vertiginoso de tais acordos promove um verdadeiro esvaziamento da regra básica existente desde os tempos do GATT 1947, estando a OMC, na realidade atual, diante de um sistema de comércio mundial distante da visão dos arquitetos do GATT.

1 O relatório foi elaborado pelo conjunto de autores de peso formado por Peter SUTHERLAND, Jagdish BHAGWATI, Kwesi BOTCHWEY, Niall FITZGERALD, Koichi HAMADA, John JACKSON, Celso LAFER e Thierry DE MONTBRIAL. 
A fraca disciplina do tema, a dificuldade em se atingir um consenso, e o interesse de grande parte dos Estados membros em deixar a temática apartada das discussões multilaterais contribuem para a erosão da não-discriminação no comércio internacional. Ademais, o efeito dominó, que causa um processo de ação e reação em que a criação de mecanismos discriminatórios por um país é acompanhada por uma reação da mesma natureza por outros países, teria tornado esta erosão irreversível (FIORENTINO; VERDEJA; TOQUEBOEUF, 2007, p. 13).

Não obstante seja inegável a atual inversão entre regra e exceção no tocante à regra da Nação Mais Favorecida, que teria se tornado a "regra da nação menos favorecida", há uma divergência tradicional na doutrina, entre os estudiosos que acreditam serem os fenômenos do multilateralismo e do regionalismo caminhos diversos, e entre aqueles que opinam pela possibilidade de aproveitamento de um pelo outro.

Ambas as correntes pugnam, entretanto, por uma postura mais ativa da OMC, sob pena de seu esvaziamento e comprometimentos graves ao futuro da organização.

Embora haja uma pluralidade de perspectivas e peculiaridades da discussão entre os autores sobre a relação entre o sistema multilateral e o regionalismo, a temática sofreu uma polarização tradicional sob as facetas do antagonismo e da complementariedade entre ambos. A teoria multilateralização do regionalismo, de outro modo, se apresenta como novo paradigma tendente a conciliar essas perspectivas em oposição.

Em resumo dos argumentos econômicos, o antagonismo entre ambos os fenômenos decorreria, economicamente, do fato do regionalismo constituir sempre a "segunda melhor opção", pois necessariamente levaria a escolhas de fornecedor menos vantajosas em algum setor ou produto, e poderia prejudicar o fluxo do comércio internacional que existiria na 
ausência do acordo, caso o volume de desvio de comércio supere o de criação de comércio (SCHOTT, 2008).

Adicionalmente, constata-se a existência de um emaranhado de acordos, com regimes regulatórios diferentes e frequentemente conflitantes entre si, ameaçando os princípios da transparência e previsibilidade no comércio internacional (FIORENTINO; VERDEJA; TOQUEBOEUF: 2007, p. 26), bem como causando o aumento dos custos de transação através dessa complexa arquitetura. Bhagwati (1996), ao tratar desse fenômeno, cunhou o famoso termo spaguetti bowl, em referência ao emaranhado de regulamentações comerciais sobrepostas e inconsistentes entre si.

Ademais, afirma-se que os Acordos Regionais de Comércio podem desviar a atenção das negociações multilaterais, por motivos de recursos financeiros e humanos limitados destinados a negociações comerciais, e por razão de mudança de foco e perda de interesse político no sistema multilateral (FIORENTINO; VERDEJA; TOQUEBOEUF, 2007 , p. 11). Por fim, não se pode ignorar que o tratamento de temas "sensíveis" pelos sistemas regionais pode prejudicar o consenso nas regras do comércio multilateral.

Sob a perspectiva de compatibilidade entre os fenômenos, por outro lado, tem-se o fato de compartilharem o objetivo de liberalização, e assim, os Acordos Regionais ao promoverem cortes no nível de tarifas favoreceriam o caminho ao livre comércio, fim precípuo do sistema multilateral (BERGSTEN, 1997).

Ademais, os arranjos regionais com frequência aprofundam os compromissos já acordados, ou incluem compromissos em áreas ainda não abrangidas pelas obrigações da OMC. O estabelecimento de 
compromissos mais profundos - WTO-plus ${ }^{2}$, e de compromissos que ultrapassam as áreas atualmente disciplinadas- WTO-extra ${ }^{3}$ (HORN; MAVROIDIS; SAPIR, 2009), pode ser interpretado como antecedente positivo às negociações multilaterais (CEPAL, 2001, p. 210).

Após décadas de debate na doutrina, recentemente tem prevalecido a ideia de que os argumentos de incompatibilidade ou compatibilidade devem ser mensurados empiricamente, a partir das especificidades dos respectivos Acordos.

A este respeito, observe-se a conclusão de estudo da CEPAL (2001, p. 211):

Se puede medir cuán cerca o lejos está el regionalismo del proceso multilateral a partir de dos condiciones: i) la profundidad del proceso, es decir, la extensión y la amplitud de las normativas acordadas entre los miembros del grupo, y ii) la capacidad de inclusión de nuevos miembros. Los conceptos de regionalismo profundo y regionalismo abierto reflejan los desafíos que se plantean a los países de las dos regiones analizadas para lograr una mejor inserción internacional. Empero, estos conceptos no deben ser encarados como normativos, sino como operacionales. El primero se refiere al grado de soberanía en materia de política económica que los gobiernos están dispuestos a sacrificar en aras de la armonización de las políticas nacionales a escala regional y multilateral. El segundo concepto apunta al tipo de relación que debe establecerse con los países no pertenecientes a los acuerdos preferenciales.

Assim, as discussões contemporâneas acerca da temática afastam-se das análises econômicas focadas em criação e desvio

2 A expressão WTO-plus é utilizada na doutrina em referência a Acordos que tratam de temas previstos na $\mathrm{OMC}$, mas estabelecem compromissos mais onerosos que a disciplina do sistema multilateral.

3 A expressão WTO-extra é utilizada na doutrina em referência a Acordos que tratam de temas ainda não disciplinados pelo sistema multilateral. 
dos fluxos de comércio e aproximam-se das análises empíricas dos respectivos acordos, focando na natureza e amplitude dos compromissos objeto de cada acordo, e dos interesses estratégicos dos membros em ampliar seus marcos regulatórios ao ambiente multilateral (BADIN, 2012; THORSTENSEN et al., 2013).

\section{ATUAL ESTÁGIO DA DISCUSSÃO: O PAPEL ESTRATÉGICO DOS ACORDOS REGIONAIS DE COMÉRCIO COMO PARADIGMA DE REGULAÇÃO}

As análises mais recentes comungam da percepção de que, diante das novas complexidades do regionalismo no século XXI, as iniciativas de regionalismo atuais buscam preencher o espaço de regulamentação de temas deixados pelo congelamento da Rodada de Doha. Dessa maneira, a sistemática de negociação passa a circular não mais em função de barganhas para o acesso a mercados através de cortes tarifários, mas em torno da capacidade de expansão de modelos regulatórios.

Isto pois a revolução tecnológica-informacional-comunicacional teria promovido verdadeira internacionalização das cadeias produtivas, que trouxe a imbricação entre (i) o comércio; (ii) os investimentos e (iii) os serviços ao centro do comércio internacional. Essa nova configuração exige normas complexas para sua regulação, que abarquem tais temáticas (BALDWIN, 2011, p. 5).

Assim, a sistemática de negociação - regional ou multilateral - e os seus interesses centrais passam a circular não mais em função de barganhas para o acesso a mercados através de cortes tarifários, mas em torno da capacidade de expansão do modelo regulatório ao qual um polo já esteja vinculado. 
De modo semelhante, Thorstensen (2011) propõe uma visão integrada da regulação do comércio global, que passaria por uma análise transversal das dimensões normativas relacionadas ao comércio internacional, o que promoveria uma melhor compreensão dos efeitos cruzados entre o sistema multilateral-plurilateral, os sistemas preferenciais, e os sistemas nacionais de comércio externo.

A autora não ignora a relevância central de uma análise cuidadosa e de mapeamento dos acordos preferenciais negociados por um certo parceiro, uma vez que a concentração de países com acordos em torno de um eixo evidencia padrões de regras que depois serão levadas às instâncias multilaterais. E, assim, se um número significativo de países adotarem certo modelo regulatório, o grau de liberdade possível para a negociação multilateral ou a posterior inclusão de outros países no grupo tende a ser limitada (THORSTENSEN, 2011, p. 98).

Diante da tendência à formação desses acordos capitaneados por atores econômicos centrais - Estados Unidos e União Europeia como meio de forçar a regulamentação doméstica nos Estados menos desenvolvidos, a normatividade que hoje parece diluída tende a se cristalizar, exatamente devido à tipologia dos compromissos abarcados, que importam implicações jurídico-institucionais domésticas duradouras (CAPUCIO, 2014).

Neste contexto, a celebração de Acordos plurilaterais, tal como o ITA e sua recente expansão, demandam cuidadosa atenção por parte dos estudiosos. Para uma melhor compreensão de seu significado no contexto mais amplo, contudo, faz-se necessário o estudo acerca da multilateralização do regionalismo e de seu significado para a reconfiguração do papel da OMC na atualidade. 


\section{A MULTILATERALIZAÇÃO DO REGIONALISMO: FUNDAMENTOS}

Em julho de 2006, Richard Baldwin apresentou na World Economy Annual Lecture trabalho denominado Multilateralizing Regionalism: Spaguetti bowls as building blocs on the path to Free Trade, posteriormente publicado em diversas revistas especializadas. Referido trabalho, que segundo o autor foi resultado de suas pesquisas desenvolvidas desde a década de 1980, propõe uma nova abordagem da relação entre o sistema multilateral e o regionalismo (BALDWIN, 2006).

Referida abordagem partia da premissa de que, considerando o alastramento dos Acordos Regionais de Comércio nos últimos anos, e o papel central de blocos consolidados como a União Europeia, MERCOSUL, NAFTA e APEC na economia internacional, o fenômeno do regionalismo constitui realidade das relações internacionais, que não pode ser negada ou evitada, mas deve ser melhor aproveitado para a geração de benefícios em processos multilaterais.

Assim, uma vez ultrapassada a tradicional oposição "regionalismo versus multilateralismo", Baldwin releva a necessidade de implementação de um novo paradigma de "regionalismo multilateralizante", cuja agilidade na harmonização de regras e obtenção de resultados compartilhados pelos Estados-membros seria capaz de fortalecer e aprofundar a liberalização multilateral do comércio.

$\mathrm{O}$ autor pretendia, portanto, desenvolver estratégias para a multilateralização do regionalismo existente e emergente, pois parte dos teóricos havia se perdido na discussão do dualismo entre os acordos regionais e a $\mathrm{OMC}$.

Segundo sua análise, em uma perspectiva histórica, as políticas 
econômicas liberalizantes e a emergência do regionalismo tem se concretizado em efeito dominó, uma vez que os efeitos de um Acordo Regional sob a economia de Estados não membros tende à levá-los também à uma adesão ao Acordo ou à liberalizações regionais próprias.

Como forma de densificar os compromissos comerciais existentes nesses grandes blocos, o autor propõe, como medidas multilateralizantes, medidas que promovam uma harmonização das regras de setores do comércio internacional, a partir de arranjos regionais já existentes.

Segundo o autor, o emaranhado de obrigações comerciais, denominado de síndrome do spaghetti bowl, se traduz concretamente em duas características básicas e inter-relacionadas: (1) regras de origem diferentes e não harmonizadas, e (2) cumulação bilateral. ${ }^{4}$ Será, portanto, sob esses dois elementos que deverão recair as medidas multilateralizantes, tendentes a "domar" o emaranhado de acordos.

As regras de origem podem ser entendidas, de forma mais pragmática, como regimes internos que os Acordos Regionais devem adotar, para certificar-se que apenas membros se beneficiem da redução de tarifas promovida pelo acordo, prevenindo dessa forma que outros países tirem vantagens das diferenças tarifárias criadas (JENSENMORAN, 1996, p. 1).

A regras de origem têm sido uma preocupação primária dos autores, negociadores e participantes do comércio internacional, vez que costumam funcionar como instrumentos de proteção disfarçada à determinados setores, pois podem onerar insumos intermediários importados ao bloco, afetando a relação de preços e a competitividade

4 É frequente também o uso da palavra acumulação para designar exatamente o mesmo mecanismo que explicamos no trabalho. 
entre produtos no interior do bloco (KRISHNA, 2005).

Assim, regras de origem muito restritivas podem causar um efetivo aumento do protecionismo face a insumos oriundos de terceiros países não membros do Acordo, ainda que as tarifas externas não tenham sido alteradas (HOEKMAN; KOSTECKI, 1995, p. 227). E, simultaneamente, incentivar o comércio de insumos de fontes no interior do bloco, ainda que estas sejam menos eficientes economicamente, como explica a autora:

ROO can also provide an incentive for regional producers to buy intermediate goods from regional sources, even if their prices are higher than those of the identical import from outside the $\mathrm{F} \mathrm{T} \mathrm{A}$, in order to make their product "originate" in the F T A and qualify for preferential treatment. This, in effect, protects F T A suppliers." (KRISHNA, 2005, p. 4).

As regras de origem são frequentemente utilizadas de forma estratégica, de modo a resguardar determinados setores dos efeitos da formação de um Acordo Regional (KRISHNA, 2005, p. 6). De fato, regras de origem podem ser instrumentos de seletividade, com os adicionais problemas de falta de transparência e aumento nos custos de transação (DEVLIN; ESTEVADEORDAL, 2001, p. 43).

Retomando o raciocínio de Baldwin, a existência de um emaranhado complexo de Acordos Regionais, já identificado como síndrome do spaguetti bowl, se caracteriza pela existência de regras de origem diferentes e não harmonizadas, consequência dos interesses específicos de grupos de pressão influentes em cada economia nacional (BALDWIN, 2006, p. 1471).

Embora seja notável a importância das regras de origem, 
essenciais à toda a dinâmica preferencial dos arranjos regionais, tendo em conta o efeito de distorção que elas podem gerar, as regras de origem deveriam ser cuidadosamente negociadas, e principalmente monitoradas, pelo sistema multilateral com vistas à garantir que não constituam um entrave abusivo ao comércio de terceiros Estados com os membros dos acordos regionais.

As regras de origem são instrumentos de determinação da origem de bens para fins de aplicação tarifária em um determinado território, objeti- vando, portanto, evitar que preferências ou restrições devidas ao comércio de um bem sejam burladas por meio da adulteração da origem do produto importado (MOTA, 2005, p. 568).

Contudo, as regras de origem têm exigido uma preocupação legítima por parte dos negociadores e participantes do comércio internacional, pois costumam atuar como instrumentos de proteção disfarçada a determinados setores, pois podem onerar insumos intermediários importados ao bloco, afetando a relação de preços e a competitividade entre produtos no interior do bloco.

De toda monta, resta claro que as necessárias iniciativas multilateralizantes devem promover uma harmonização das regras de origem, havendo aqui a oportunidade para que a OMC retome seu papel central na negociação das regras do comércio internacional.

No que se refere ao segundo elemento, cumulação é um termo técnico que designa o sistema pelo qual países que possuem as mesmas regras de origem permitam que produtos originados em um primeiro país sirvam de insumos a serem processados e/ou adicionados em um outro país, sem que isso afete o status do produto final como originário do segundo país.

São, assim, instrumentos adotados em complementariedade 
às regras de origem, objetivando corrigir eventuais distorções das regras de origem no fluxo concreto do comércio internacional de bens manufaturados, e permitindo uma flexibilização necessária na aplicação das regras de origem.

Retomando o raciocínio de Baldwin, o autor identifica que a existência de um emaranhado complexo de Acordos Regionais, síndrome do spaguetti bowl, se caracteriza também pela existência de regras de cumulação bilateral, ao passo que essas permitem uma aplicação mais restritiva dos sistemas de regras de origem e a consequente distorção do padrão de consumo de insumos intermediários (BALDWIN, 2006, p. 1481).

Assim, resta claro que um dos aspectos das medidas de multilateralização é a substituir a cumulação bilateral pelos demais tipos de cumulação, quais sejam a cumulação bilateral, a diagonal e a total:

In bilateral cumulation, the use of the partner country components is favored; in diagonal cumulation, all the beneficiary trading partners of the cumulation area are favored. Full cumulation is more liberal than diagonal cumulation by allowing a greater use of third-country materials. However, it is rarely allowed in $\mathrm{RoO}$ regimes (ESTEVADEORDAL; SUOMINEN, 2004, p. 6).

Diante das maiores complexidades da cumulação completa, o autor propõe, portanto, a adoção de cumulação diagonal, como modo de impedir que as regras de origem exerçam influência nas escolhas de fornecedores entre os Estados membros da zona de cumulação, e os permitam, portanto, realizar a escolha mais eficiente. Nessa questão novamente há espaço para a coordenação pelo sistema multilateral de comércio. 
Para basear empiricamente suas proposições, Baldwin cita duas experiências históricas como exemplos de multilateralização do regionalismo: o Sistema Pan-Europeu de Cumulação (Pan-European Cumulation System - PECS)e o Acordo de Tecnologia da Informação (Information Technology Agreement - ITA).

O Sistema Pan-Europeu de Cumulação (PECS) foi formulado em 1997, como instrumento para sanar os malefícios oriundos de uma variedade de regras de origem e de cumulação desconexas, pertencentes a um emaranhado de Acordos Preferenciais dos quais a UE fazia parte, efeitos colaterais da síndrome do spaguetti bowl.

A União Europeia promoveu, então, através da constituição do PECS duas mudanças principais: (1) a harmonização de regras de origem, para evitar os custos de preencher os requisitos de documentação de diferentes sistemas de origem; e (2) a permissão de cumulação diagonal, que amplia as fontes de insumos para aquelas localizadas em toda a área do PECS sem ameaçar o status do produto final como originário da União (GASIOREK; AUGIER; LAI-TONG, 2009, p. 155).

Por sua vez, o Acordo de Tecnologia da Informação (Information Technology Agreement - ITA), que é objeto de analise mais detida neste trabalho, foi um acordo plurilateral relativo ao mercado de tecnologia da informação, que se encontrava em um contexto de liberalizações unilaterais, regionais e multilaterais. A partir da iniciativa de um grupo de membros da Organização Mundial do Comércio, esta temática foi multilateralizada à participação dos demais.

\section{O INFORMATION TECHNOLOGY AGREEMENT COMO EXPERIÊNCIA HISTÓRICA DE MULTILATERALIZAÇÃO}


Inserido na proposição de multilateralização do regionalismo, o Acordo de Tecnologia da Informação (ITA) é indicado como um exemplo da possibilidade de tal fenômeno, e em especial da coordenação dessa iniciativa por parte da OMC.

O mercado de tecnologia da informação se encontrava envolto por um emaranhado de liberalizações unilaterais, regionais e multilaterais, entretanto a cumulação bilateral e regras de origem não-harmonizadas afastavam o setor da situação real de livre comércio.

Em 1996, contudo, as principais economias produtoras se encontraram sob os auspícios da $\mathrm{OMC}$, o que resultou na assinatura do ITA. O ITA possui características distintivas e é considerado um sucesso de normatização setorial, vez que estabeleceu tarifas zero em ampla cobertura de produtos estabelecidos previamente, sob o Princípio da Nação Mais Favorecida, e com cronograma de reduções previamente acordado e implementado (MANN; LIU, 2009, p. 182).

O ITA surgiu, primeiramente, como iniciativa dos EUA, tendo havido posterior apoio de players como a UE e Japão, e possuía como claro objetivo o estabelecimento do livre comércio no setor. De fato, o Acordo previa que somente entraria em vigor caso os signatários completassem uma fatia de $90 \%$ do comércio mundial no setor, o que veio a ser atingido em 1997 com mais algumas ratificações.

Segundo Baldwin, teria havido uma situação de efeito dominó, que poderia ser implementada em demais setores:

Just as with PECS, the ITA created a domino effect as smaller nations signed up to the ITA as a means of boosting the attractiveness of their nation to foreign IT producers. A steady stream of WTO members has signed the ITA; there are now 63 signatories which account for about 97 percent of world IT trade (BALDWIN, 2006, p. 1485) 
Assim como a inversão no jogo de interesses dos produtores tende a pressionar por uma homogeneização e relaxamento nas regras de origem, Baldwin tira da experiência do ITA a conclusão de que liberalizações multilaterais setoriais promovidas pelos principais players do comércio internacional criam um efeito dominó que incentiva os demais a participarem da iniciativa multilateralizante.

O autor destaca, portanto, a previsão de existência de três grandes polos de emaranhados de Acordos Regionais - a partir da Europa, América do Norte e Ásia - para afirmar que pode haver uma tendência semelhante ao ITA em outros setores, na qual as forças políticas de seus epicentros pressionariam pela celebração de acordos de liberalização setorial multilateral.

E assim, a tendência à inversão dos interesses políticos e à posterior multilateralização seria processo capaz de levar a ordem econômica ao livre comércio, a partir do protagonismo destes três epicentros, e o exercício de seu papel como building blocks.

Embora tenha um caráter especulativo, o ITA pode ser apontado como um precedente de sucesso na multilateralização, como resultado próprio dos interesses econômicos de seus produtores em usufruir da liberalização não-discriminatória, vez que todo membro da OMC pode usufruir da eliminação de tarifas.

Entretanto, Mann e Liu (2009, p. 183) após realizar estudo focado no Acordo, destacam a existência de certas especificidades dos produtos do mercado de tecnologia da informação que tornaram o ITA uma iniciativa de sucesso, mas que não necessariamente estariam presentes em outros setores - tais como suas elasticidade-preço e elasticidaderendimento, sua grande contribuição para o aumento de produtividade nas 
economias e grande dependência da cadeia internacional de fornecedores.

Os autores concluem, portanto, que embora seja um bom legado como ponto de partida para a discussão e o desenvolvimento de outras iniciativas no âmbito da $\mathrm{OMC}$, estes fatores que o diferenciam tornam o ITA uma experiência sui generis, sem garantia de sucesso para experiências posteriores cujos mercados tenham características distintas (MANN; LIU, 2009, p. 213).

É explícito, ainda, que os dois exemplos de multilateralização do regionalismo trazidos à baila pelo seu entusiasta se contrastam quanto ao papel da OMC. Se o ITA foi resultado de negociações conduzidas na sistemática da OMC, o PECS foi concebido, negociado e implementado por uma das hegemonias do comércio internacional, a União Europeia.

Embora não seja possível generalizar a partir destas duas experiências, a perspectiva de interpretação explicitada por Baldwin caminha no sentido de que o envolvimento da OMC no ITA tenha produzido uma multilateralização do regionalismo de maneira muito mais aberta e menos hegemônica que no PECS (BALDWIN, 2006, p. 1488).

Por fim, de forma mais geral, a partir do paradigma de multilateralização sob análise, é possível indicar outras maneiras que possivelmente promoverão a multilateralização dos esquemas regionais, e o seu consequente aproveitamento pelo sistema multilateral de comércio.

Cita-se a esse respeito, as seguintes medidas que de modo geral possam contribuir para a concretude da multilateralização (BALDWIN; EVENETT; LOW, 2009, p. 81):

(a) a expansão geográfica dos $\mathrm{ARC}$, ou de um conjunto de medidas aplicadas;

(b) a inclusão em ARC de disposições da regra da Nação Mais Favorecida no que tange a determinados setores e medidas; 
(c) regras acordadas em ARC que tornem na prática a discriminação indesejável ou inviável;

(d) a inclusão de clausula da Nação Mais Favorecida em relação a terceiros, que garantam aos signatários de Acordos existentes a manutenção dos seus benefícios quando da formação de ARC subsequentes;

(e) a inclusão de disposições que previnam que ações permitidas sob a disciplina dos Acordos da OMC sejam consideradas tratamento discriminatório.

Tendo em vista as possíveis medidas de multilateralização apresentadas, a OMC é convidada a desempenhar relevantes funções neste contexto, como passamos a observar.

O posicionamento passivo da OMC diante da avalanche de Acordos Regionais observada nas últimas décadas gera preocupações, principalmente quanto à diminuição de sua credibilidade e protagonismo internacional. E isso tendo em vista, ainda, a sua real capacidade e oportunidade de desempenhar um papel essencial de vetor dos benefícios do regionalismo na liberalização multilateral. Nos dizeres de Baldwin (2006, p. 1488):

The WTO risks a serious erosion of its relevance if it continues in its 'innocent bystander' role. Moreover, the WTO is probably the only international organisation that is well-placed to help tame the tangle of free trade deals at the global level; it is probably the only international organisation that has a clear incentive to do so.

De fato, as principais questões envolvidas na multilateralização 
de Acordos Regionais de Comércio consistem nas regras de origem e regras de cumulação, e suas possíveis consequências em terceiros países. São portanto questões altamente complexas, cuja compreensão exige conhecimentos econômicos e jurídicos extremamente técnicos.

É claro, a esse ponto, um primeiro papel que pode ser desempenhado pela $\mathrm{OMC}$, na produção de pesquisas neutras que estudem melhor o impacto desses acordos e sua dinâmica no comércio internacional. Esse esforço pode auxiliar não somente os países menos desenvolvidos, mas de fato contribuir politicamente para um esforço de difusão do multilateralização do regionalismo entre os Estados, a partir de uma melhor compreensão de seus efeitos e identificação de questões críticas e implicações técnicas do processo.

Uma segunda questão é que a necessidade de harmonização das regras de origem ou ao menos do estabelecimento de regras mínimas comuns, se apresenta como uma excelente oportunidade para que a OMC promova a discussão entre os maiores players sobre a questão, e os convoque para negociação, na busca de acordos mutuamente benéficos.

Iniciativas regionais de harmonização de regras de origem, como a promovida pela UE na Europa e a promovida pelos EUA na América do Norte e Central, podem ser citadas como exemplos hegemônicos desse tipo de negociação.

Assim, o autor destaca, ainda, que embora as regras de origem em setores sensíveis sejam terrenos áridos politicamente, seria possível a negociação e o estabelecimento de standards internacionais para regras preferenciais de origem em áreas menos sensíveis.

A esse exemplo é citado que organizações como a International Standards Organisation (ISO) gerenciam com sucesso standards comuns em vários, mas não na totalidade de produtos, estabelecidas através de 
mútuas negociações.

Ademais, o impacto da globalização sob o paradigma produtivo tende a desagregar as etapas de produção, criando maior número e diferenciação entre elas, o que contribui para aumentar os benefícios às empresas com a harmonização das regras de origem, vez que inverte a mesa sob a qual estão os jogos de interesse (BALDWIN, 2006, p. 1489).

Uma terceira função que pode ser desempenhada pela OMC, e que pressupõe as duas primeiras, trata-se do auxílio à países em desenvolvimento na constituição de Acordos Regionais que lhes sejam menos assimétricos e prejudiciais. Esta função se daria indiretamente, através de informações mais claras fornecidas pelo Secretariado e de negociações multilaterais, que aumentam os potenciais ganhos do grupo de países em desenvolvimento, se comparados com negociações bilaterais. Esse auxílio pode ser implementado também de maneira mais direta, através por exemplo da constituição de um centro de aconselhamento especificamente voltado às análises econômicas de Acordos Norte-Sul e Sul-Sul.

O exercício destes e de demais papéis correlatos na multilateralização do regionalismo pela $\mathrm{OMC}$, como se tem demonstrado, é factível e pode ser essencial para que a organização mantenha seu protagonismo na ordem econômica internacional, ameaçado pelo regionalismo sem limites. Assim, além da geração de ganhos multilaterais com a tendência do regionalismo, será possível a diminuição da "lei da selva" nas relações do comércio internacional, não raro predominante nos arranjos regionais assimétricos.

\section{RECENTE EXPANSÃO DO ITA}


O Acordo de Tecnologia da Informação original foi celebrado em 13 de dezembro de 1996, por meio da "Declaração Ministerial sobre o Comércio de Produtos de Tecnologia da Informação”, na Conferência Ministerial de Singapura, sendo, assim, o primeiro acordo significativo de liberalização tarifária negociada na OMC após a sua criação, em 1995. O acordo entrou em vigou no ano seguinte de sua celebração, completando em 2017 duas décadas de sua entrada em vigor.

O Acordo de Tecnologia da Informação abarca uma extensa gama de produtos de alta tecnologia, tais como computadores, softwares, semicondutores, equipamentos de telecomunicações, instrumentos científicos e peças e acessórios de produtos de alta tecnologia. Este é um dos setores de maior e mais acelerado crescimento no comércio mundial, estimando-se que o comércio de tais produtos seja responsável por aproximadamente 10 por cento das exportações mundiais de mercadorias (WTO, 2015).

Segundo o Acordo, os participantes devem eliminar os direitos aduaneiros para os produtos especificados no Acordo. Há que se destacar, ainda, que como as concessões do Acordo estão incluídas nas programações de concessões dos participantes, a eliminação de tarifas ocorre com base na nação mais favorecida (NMF). Isto significa que, mesmo os países que não aderiram ao ITA podem se beneficiar das oportunidades comerciais geradas pela eliminação de tarifas ITA.

Em maio de 2012, tendo em vista que a evolução tecnológica ocorrida nas últimas décadas trouxe novas categorias de produtos de TI, os membros da OMC consideraram que a cobertura de produtos do ITA deveria ser expandida. Assim, em junho de 2012, alguns membros da OMC tomaram a iniciativa de instaurar negociações para a expansão da cobertura de produtos do ITA. Passou-se à criação de um grupo técnico 
de trabalho que se reuniu informalmente em Genebra, e que comandou as negociações de expansão do âmbito dos produtos (WTO, 2015).

Após diversas sessões de negociações, em reunião de 24 de julho de 2015, a ampla maioria dos participantes concordou em expandir os produtos abrangidos pelo Acordo de Tecnologia da Informação, eliminando suas respectivas tarifas sobre uma lista adicional de 201 produtos. $\mathrm{O}$ acordo conta com a participação de diversos países asiáticos, como China, Taiwan, Tailândia e Coreia.

A recente expansão do ITA é justificada, segundo o Secretário geral da $\mathrm{OMC}$, não somente pela intenção de eliminar tarifas e expandir o comércio desses produtos, mas trata-se também de um estímulo à inovação e desenvolvimento e expansão de novas tecnologias e sia disponibilização mais barata às comunidades, incrementando sua conectividade (WTO, 2017). Nesta linha de análise, para além dos objetivos comerciais da Organização, o ITA e sua recente expansão estariam contribuindo para um dos Objetivos do Desenvolvimento Sustentável da ONU, por meio da ampliação do acesso internet, reduzindo a distância digital existente entre os povos (WTO, 2017).

Estima-se que o comércio anual desses 201 produtos esteja avaliado em mais de 1,3 trilhões por ano, e representa cerca de $10 \%$ do comércio mundial de mercadorias (OSAKWE, 2015, p. 9; WTO, 2017). Assim, passou-se a abranger, por exemplo, uma nova geração de produtos tecnológicos, bem como equipamentos de navegação GPS, lentes óticas e certos equipamentos médicos.

De fato, outro benefício não econômico resultante da expansão do ITAé a ampliação do acesso e a diminuição dos custos de equipamentos médicos, o que pode ter um impacto positivo na saúde pública dos diferentes Estados ao redor do globo. Segundo dados da OMC, 4,8\% da 
exportação total de produtos com base na regulamentação do ITA II se refere à categoria dos equipamentos médicos (WTO, 2017, p. 72).

Quase todos os participantes já confirmaram a sua aceitação da nova lista de cobertura de produtos e juntos tais membros representam cerca de $90 \%$ do comércio mundial dos produtos incluídos por este novo instrumento (WTO, 2015).

Tendo em vista os termos do acordo, a maioria das tarifas serão eliminadas nos 201 produtos dentro de três anos, e as reduções se iniciaram em 2016.

O acordo prevê ainda outros compromissos, como a eliminação de barreiras não-tarifárias neste setor e a previsão de periódica revisão da lista de produtos abrangidos, tendo em vista evolução tecnológica futura. Acerca dos compromissos adicionais, no tocante à eliminação de barreiras não tarifárias, observa-se que o Acordo caminha na tendência recentemente identificada de tratamento de aspectos regulatórios, trazendo consigo os riscos de imposição de um modelo predominante que já satisfaça a interesses hegemônicos dos principais atores do sistema - EUA e União Europeia.

Contudo, é preciso lembrar que o Acordo original, agora denominado de ITA I, e a recente expansão, denominada ITA II, são acordos plurilaterais de natureza aberta (ICTSD, 2015). Isto é, embora não sejam acordos incluídos nos compromissos que vinculam todos os membros da OMC, mas somente aqueles que decidiram se vincular a ele, são acordos cujos benefícios são estendidos à amplitude dos participantes do comércio global, por meio do princípio da nação mais favorecida (CAPUCIO, 2015).

É relevante destacar, por fim, o papel paradigmático do ITA II como revelador da possibilidade de expansão do poder normativo do 
sistema multilateral de comércio por meio de Acordos plurilaterais desta natureza. Assim, em caminho semelhante ao trilhado pelos membros para celebração de tal Acordo, está em fase de negociação o Acordo TISA (Trade in Services Agreement), que busca promover uma espécie de aceleração da liberalização em serviços aos membros que assim desejarem (PENG, 2013).

\section{CONSIDERAÇÕES FINAIS}

A expansão do regionalismo gerou a necessidade de enfrentamento da reflexão acerca do papel dos acordos regionais de comércio na sistemática do comércio internacional na atualidade. Sendo esta uma realidade inelutável das relações comerciais internacionais, devem ser buscados instrumentos para a concretização dos benefícios da integração regional também em âmbito multilateral.

A teoria de multilateralização do regionalismo propõe um paradigma de compatibilização do regionalismo, convocando a Organização Mundial do Comércio para um papel mais ativo na temática do regionalismo. Um dos exemplos de concretização dessa teoria é o Acordo sobre Tecnologia da Informação, que sofreu recente expansão em seu escopo setorial e material.

A recente expansão do Acordo se preocupa também com os ganhos indiretos, uma vez que, para além dos ganhos diretos para a indústria de TI resultantes da eliminação dos direitos de importação, pode-se esperar que os demais agentes econômicos envolvidos, tais como investidores e comerciantes, também se beneficiarão com a redução ou eliminação de barreiras e com a expansão da previsibilidade e da segurança. 
A previsão de um acordo aberto, isto é, com ampliação dos benefícios aos demais membros da OMC em função do princípio da nação mais favorecida, reforça a sua potencialidade em gerar benefícios econômicos em uma base não discriminatória, e pode se consolidar como um exemplo para a liberalização em outros setores.

Por outro lado, contudo, deve haver uma precaução cuidadosa no simples replicamento deste exemplo sem uma reflexão mais ampla. Isto pois os arranjos regionais contemporâneos se localizam como tentativa de expansão de modelos regulatórios, buscando preencher o espaço de regulamentação de temas deixados pela agenda multilateral.

Neste cenário, a decisão do Brasil de não participar desta iniciativa pode ser prejudicial ao país não sob a perspectiva de não de beneficiar de acesso a mercados ou de não ampliar o acesso de seu mercado aos produtos estrangeiros - o que poderia favorecer o consumidor nacional em uma perspectiva mais ampla - mas pela não inserção do país na negociação e implementação de parâmetros regulatórios que tendem a ser os dominantes no setor.

Há de se destacar, neste contexto, que está-se em face de uma considerável mudança no papel da OMC desde a sua criação. Tal instituição permanece como um dos pilares s do comércio internacional, principalmente em função do seu sistema de solução de controvérsias e de seu arcabouço normativo, em relação ao qual não há retrocesso.

Contudo, sua capacidade de avançar no sentido de alcançar novos consensos e novos compromissos exige uma rearquitetura da relação entre as iniciativas preferenciais e o ambiente multilateral, em um contexto de governança econômica global em um sentido mais amplo. 


\section{REFERÊNCIAS}

BALDWIN, Richard. Multilateralizing regionalism: spaguetti bowls as building blocs on the path to global free trade. The World Economy, Oxford, v. 29, n. 11, p. 1451-1518, 2006.

BALDWIN, Richard. 21th Century Regionalism: filling the gap between 21 th century trade and 20th century rules. Geneva: World Trade Organization, Economic Research and Statistics Division, 2011. p. 23-25.

BALDWIN, Richard; EVENETT, Simon; LOW, Patrick. Multilateralizing Non-Tafiff RTA Commitments. In: BALDWIN, Richard; LOW, Patrick. Multilateralizing regionalism: challenges for the global trading system. Cambridge: Cambridge University Press, 2009. Chapter 3.

BERGSTEN, Fred. Open regionalism. The World Economy, Oxford, v. 20, n. 5, p. 545-565, ago. 1997.

BHAGWATI, Jagdish. Preferential trade agreements: the wrong road. Law and Policy in International Business, Washington, v. 27, p. 865-90, 1996.

CAPUCIO, Camilla. O princípio da nação mais favorecida e o sistema multilateral de comércio. In: PATROCÍNIO, Daniel Moreira do.

Princípios jurídicos. Rio de Janeiro: Lumen Juris, 2015.

CAPUCIO, Camilla. A OMC e o regionalismo do século XXI: estratégia de imposição de modelos normativos? Revista Brasileira de Direito Internacional, Brasília, v. 11, n. 2, p. 337-348, 2014.

CEPAL. Regionalismo abierto: un examen del concepto a la luz de las experiencias de América Latina y Asia y el Pacífico. In: 
Panorama de la inserción internacional de América Latina y el Caribe. Santiago: Naciones Unidas, 2001. Cap. VII.

SUTHERLAND, Peter et al. The future of the WTO: Addressing institutional challenges in the new milenium. Geneva: WTO, 2004.

DEVLIN, Robert; ESTEVADEORDAL, Antoni. What's New in the New Regionalism in the Americas?, In: BULMER-THOMAS. Victor. (Ed.). Regional Integration in Latin America and the Caribbean: the political economy of open regionalism. London: Institute of Latin American Studies, University of London, 2001. Cap. 1.

ESTEVADEORDAL, Antoni; SUOMINEN, Kati. Rules of Origin: a world map and trade effects. Washington: The World Bank, 2004. Disponível em: <https://www.gtap.agecon.purdue.edu/resources/ download/1866.pdf> Acesso em: 10 jul. 2017.

FIORENTINO, Roberto; VERDEJA, Luis; TOQUEBOEUF, Christelle. The changing landscape of regional trade agreements: 2006 Update. Geneva: WTO, 2007. WTO Discussion Paper n. 12.

GASIOREK, Michael; AUGIER, Patricia; LAI-TONG, Charles. Multilateralizing Regionalism: Lessons from the EU Experience in Relaxing Rules of Origin. In: BALDWIN, Richard; LOW, Patrick. Multilateralizing regionalism: challenges for the global trading system. Cambridge: Cambridge University Press. 2009. Cap. 4.

HOEKMAN, Bernard. KOSTECKI, Michel. The Political Economy of the World Trading System: from GATT to WTO. Oxford: Oxford University Press, 1995.

HORN, Henrik; MAVROIDIS, Petros C.; SAPIR, André. Beyond the WTO? An anatomy of $E U$ and $U S$ preferential trade agreements. Brussels: Bruegel, 2009. Bruegel Blueprint Series, v. VII. 
ICTSD - INTERNATIONAL CENTRE FOR TRADE AND SUSTAINABLE DEVELOPMENT. Trade negotiators clinch tentative deal to expand ITA Product List. 2015. Disponível em: $<$ http://www.ictsd.org/bridges-news/bridges/news/trade-negotiatorsclinch-tentative-deal-to-expand-ita-product-list>. Acesso em: 10 jul. 2017.

JENSEN-MORAN, Jeri. Choice at the crossroads: regionalism and rules of origin. Law and Policy in International Business, Washington, v. 27, n. 4, p. 981-989, 1996.

KRISHNA, Kala. Understanding Rules of Origin. Cambridge: National Bureau of Economic Research, 2005.

MANN, Catherine; LIU, Xuepeng. The Information technology agreement: sui generis or model stepping stone? In: BALDWIN, Richard; LOW, Patrick. Multilateralizing regionalism: challenges for the global trading system. Cambridge: Cambridge University Press, 2009. Chapter 5.

MOTA, Pedro Infante. O Sistema GATT/OMC: introdução histórica e princípios fundamentais. Coimbra: Almedina, 2005.

OSAKWE, Chiedu. Multilateral trading system: why the wto remains indispensable? Asian Journal of WTO \& International Health Law \& Policy, v. 10, p. 1-25, 2015.

PENG, Shin Yi. Is the Trade In Services Agreement (Tisa) a Stepping Stone for fhe next version of GATS? Hong Kong Law Journal, Hong Kong, v. 43, p. 611-632, 2013.

BADIN, Michelle Ratton Sanchez. Compromissos assumidos por grandes e médias economias em acordos preferenciais de 
comércio: o contraponto entre Uniao Europeia e Estados Unidos e China e Índia. Brasília: IPEA, 2012. Texto para Discussão No. 1700.

SCHOTT, Jeffrey J. The Future of the multilateral trading system in a multi-polar world. Bonn: Deutsches Institut für Entwicklungspolitik - DIE, 2008.

THORSTENSEN, Vera. O multissistema da regulação do comércio global: proposta de novo referencial teórico e nova metodologia de análise. Revista Tempo do Mundo, Brasília, Instituto de Pesquisa Econômica Aplicada, v. 3, n. 1. p. 89-115, 2011.

THORSTENSEN, Vera et al. A multiplicação dos acordos preferenciais de comércio e o isolamento do Brasil.

2013. Disponível em: <http://retaguarda.iedi.org.br/midias/ artigos/51d18e9168afa9d0.pdf>. Acesso em: 10 jul. 2017.

\section{WTO - WORLD TRADE ORGANIZATION. Information} technology agreement: an explanation. 2015. Disponível em: $<$ https://www.wto.org/english/tratop_e/inftec_e/itaintro_e.htm $>$. Acesso em: 10 jul. 2017.

WTO - WORLD TRADE ORGANIZATION. 20 Years of the information technology agreement. Boosting trade, innovation and digital connectivity. Geneva: WTO, 2017. 44

Como citar: CAPUCIO, Camilla; KALLAS E CAETANO, Fernanda de Araújo. O Acordo da OMC sobre Tecnologia da Informação (ITA) e sua expansão (ITA II): multilateralização do regionalismo. Scientia Iuris, Londrina, v. 22, n. 1, p. 283-313, mar. 2018. DOI: 10.5433/2178-8189.2018v22n1p283. ISSN: $2178-8189$

Recebido em: 13/08/2017

Aprovado em: 19/11/2017 